JOURNAL OF MANAGEMENT OF AQUATIC RESOURCES

Volume 2, Nomor 3, Tahun 2013, Halaman 197-202

Online di : http://ejournal-s1.undip.ac.id/index.php/maquares

\title{
KAJIAN HASIL TANGKAPAN DAN TINGKAT KESEJAHTERAAN NELAYAN DI DESA AROMAREA DISTRIK KOSIWO, KABUPATEN SARUI KEPULAWAN YAPEN, PAPUA
}

Ethan Yapanani, Anhar Solichin, Bambang Argo W *)

Jurusan Perikanan, Fakultas Perikanan dan Ilmu Kelautan, Universitas Diponegoro Jl. Prof. H. Soedharto, SH, Tembalang Semarang. 50275 Telp/Fax (024) 7474698

\begin{abstract}
Abstrak
Nelayan Tradisional adalah nelayan yang memanfaatkan sumber daya perikanan dengan peralatan tangkap tradisional, modal usaha yang kecil, dan teknologi penangkapan yang relatif sederhana. Akibat keterbatasan teknologi, ruang gerak nelayan tradisional sangat terbatas, mereka hanya mampu beroperasi di perairan pantai. Hal ini membuat Masyarakat Aromarea Distrik Kosiwo harus memiliki pemahaman yang baik agar masalah sosial yang dihadapi dapat diatasi secara efisien dan efektif. Tujuan penelitian ini untuk mengetahui tentang hasil tangkapan dan tingkat kesejahteraan nelayan tradisional dengan alat tangkap jaring insang (gillnet). Dan mengetahui kondisi sosial dan ekonomi Masyarakat Desa Aromarea Distrik Kosiwo Papua. Penelitian ini menggunakan metode field research, tujuannya adalah mendeskripsikan secara detail tentang latar belakang, sifat serta karakter yang khas dari subyek penelitian tersebut. Metode pengambilan sampel menggunakan metode purposive sampling. Pengambilan data dilakukan di Desa Aromarea Kepulauan Yapen Papua. Data tersebut disajikan dalam bentuk tabulasi kemudian di analisis secara deskriptif, yang menghasilkan investasi atau modal, biaya total, pendapatan, dan keuntungan sehingga diperoleh tingkat kesejahteraan nelayan tradisional di Desa Aromarea. Analisis keragaan ekonomi secara undiscounted criterion menunjukkan bahwa usaha perikanan jaring gillnet di Desa Aromarea menguntungkan, efisien dan layak beroperasi dengan nilai R/C ratio sebesar 1,7 serta rentabilitas sebesar $62 \%$ dan payback period (PP) sebesar 1,6. Dan tingkat kesejahteraan nelayan jaring gillnet dengan metode Nilai Tukar Nelayan (NTN) diperoleh hasil NTN pada bulan Juli sebesar 1,4. Hal ini memberikan informasi bahwa keluarga nelayan mampu memenuhi kebutuhan sekunder atau tersiernya dan mampu menyisihkan uang untuk ditabung sebesar Rp. 829.546,00. Jadi, secara umum kehidupan nelayan mempunyai tingkat kesejahteraan cukup baik.
\end{abstract}

Kata Kunci: Nelayan Tradisional, Tingkat Kesejahteraan, Desa Aromarea Kepulauan Yapen Papua.

\begin{abstract}
Traditional fishermen are fishermen who exploit fishery resources with traditional fishing equipment, small business capital, and the technology is relatively simple. Due to technological limitations, traditional fishing space is very limited, they are only able to operate in coastal waters. This makes Aromarea Society District Kosiwo must have a good understanding that social problems encountered can be solved efficiently and effectively. The purpose of this study is to know about the catch and level of prosperity traditional fishermen with gillnet fishing gear (gillnet). And to know the social and economic condition of the Community Aromarea Village District Kosiwo Papua. This study uses field research, the aim is to describe in detail about the background, nature and distinctive character of the study subjects. The sampling method using purposive sampling method. Data collection was conducted in the village of Papua Aromarea Yapen Islands. The data are presented in the form of tabulation later in the descriptive analysis, which results or capital investment, total cost, revenue, and profits in order to obtain the level of welfare of traditional fishermenintheAromareaVillage. Economic variability analysis the undiscounted criterion shows that gillnet fisheries in Aromarea Village profitable, efficient and feasible to operate the $\mathrm{R} / \mathrm{C}$ ratio of 1.7 and profitability by $62 \%$ and the payback period (PP) of 1.6. And level of prosperity of gillnet fishing by the method of Exchange Fishermen (NTN) results obtained in July by 1,4. This gives the information that the fishermen family is able to meet the needs of fishermen secondary or tertiary and able to set aside money for savings of Rp. 829,546.00. So, the general life of the fishermen have a good enough level of prosperity.
\end{abstract}

Keywords: Traditional Fishermen, Level of Prosperity, Aromarea Village Yapen Islands Papua. 


\section{PENDAHULUAN}

Secara umum, yang disebut nelayan tradisional adalah nelayan yang memanfaatkan sumber daya perikanan dengan peralatan tangkap tradisional, modal usaha yang kecil, dan teknologi penangkapan yang relatif sederhana. Dalam kehidupan sehari-hari, nelayan tradisional lebih berorientasi pada pemenuhan kebutuhan sendiri.

Dalam arti hasil alokasi hasil tangkapan yang dijual lebih banyak dipergunakan untuk memenuhi kebutuhan pokok sehari-hari, khususnya pangan, dan bukan diinvestasikan kembali untuk pengembangan skala usaha (Kusnadi, 2002).

Hal ini membuat Masyarakat Aromarea Distrik Kosiwo harus memiliki pemahaman yang baik agar masalah sosial yang dihadapi dapat diatasi secara efisien dan efektif. Rendahnya Sumber Daya Manusia (SDM) dan peralatan yang digunakan nelayan berpengaruh pada penangkapan ikan. Keterbatasan dalam pemahaman akan teknologi, menjadikan kualitas dan kuantitas tangkapan tidak mengalami perbaikan di daerah tersebut. Sarana atau alat tangkap yang digunakan dalam usaha penangkapan ikan di Kepulauan Yapen pada umumnya jaring gillnet. Ayodhya (1981), mengemukakan bahwa yang dimaksud dengan jaring gillnet adalah jaring yang berbentuk empat persegi panjang, mempunyai ukuran mata jaring yang sama pada seluruh bagian jaring agar ikan lebih mudah terjerat (gilled) pada mata jaring ataupun terbelit (entangled) pada badan jaring. Penelitian ini penting dilakukan karena untuk memberikan informasi tentang hasil tangkapan dan tingkat kesejahteraan nelayan tradisional dengan alat tangkap jaring insang (gillnet) serta mengetahui kondisi sosial dan ekonomi Masyarakat Desa Aromarea Distrik Kosiwo Papua.

Secara umum, persoalan yang dihadapi masyarakat nelayan berkisar pada hal-hal yang berhubungan dengan : (1) kemiskinan dan kesenjangan sosial, (2) keterbatasan akses modal, teknologi, pasar, (3) kualitas SDM rendah. Masalah tersebut telah menimbulkan dampak negatif yang luas terhadap kehidupan masyarakat nelayan. Adapun tujuan diadakannya penelitian ini adalah untuk mengetahui tingkat kesejahteraan nelayan (gillnet) Desa Aromarea Kepulauan Yapen Papua dan mengetahui kondisi sosial dan ekonomi Masyarakat Desa Aromarea Distrik Kosiwo Papua.

Manfaat penelitian ini diharapkan mampu memberikan informasi tentang aspek sosial ekonomi serta tingkat kesejahteraan nelayan jaring insang (gillnet) yang ada di Desa Aromarea.

\section{MATERI DAN METODE}

Penelitian ini dilaksanakan pada bulan Juli 2012, di wilayah perairan Kepulauan Yapen, tepatnya di Desa Aromarea, Papua. Metode pengambilan sampel yang digunakan pada penelitian ini ialah metode purposive sampling. Metode purposive sampling ialah metode pengambilan sampel yang tidak acak (random sampling), dimana sampel dipilih berdasarkan pertimbangan-pertimbangan tertentu. Pertimbangan-pertimbangan yang dipakai sebagai dasar pengambilan sampel adalah :

1. Unit masyarakat nelayan penangkapan ikan yang menjadi obyek peneliti adalah nelayan mengunakan jaring insang gillnet, dimana jumlahnya ada 88 orang.

2. Perahu yang digunakan dalam aktivitas penangkapan ikan selalu mendaratkan hasil dan menjual hasil tangkapannya masyarakat luas di pasar ikan.

3. Pada penelitian ini, obyek yang diambil sebagai sampel dari masyarakat nelayan jaring insang gillnet untuk analisis kesejahteraan nelayan dengan metode NTN dan sebanyak perahu yang digunakan unit untuk analisis keragaan ekonomi usaha perikanan. Menurut Riduwan (2006), teknik sampling jenuh atau total sampling merupakan sampel yang mewakili jumlah populasinya, biasanya dilakukan jika populasi dianggap kecil atau kurang dari 100 (seratus). Sedangkan Arikunto (2002) menyatakan apabila populasi kurang dari 100 (seratus) lebih baik diambil semua sehingga penelitiannya merupakan penelitian populasi.

Metode analisis data pada penelitian ini dilakukan dengan cara mendapatkan jumlah keuntungan dari pekerjaan utama, yaitu dengan cara menghitung semua pendapatan yang diterima dari pekerjaan menangkap ikan oleh nelayan gillnet setelah itu dikurangi dengan biaya total. Sedangkan tingkat kesejahteraan nelayan dihitung menggunakan nilai tukar nelayan dengan cara pendapatan usaha perikanan ditambah dengan pendapatan sampingan dibagi dengan pengeluaran usaha perikanan, pengeluaran keluarga, dan pengeluaran pekerjaan tambahan nelayan. Menurut Sutojo (2000), suatu proyek memiliki umur ekonomis (economic life) tahunan bisa kurang dari 5 tahun bahkan dapat mencapai puluhan tahun. Proyek maupun merencanakan investasi yang memiliki umur ekonomis di atas 5 tahun, agak sukar untuk melakukan perhitungan-perhitungan, khususnya ramalan mengenai perkembangan ekonomi di masa-masa mendatang. Permasalahan peramalan perkembangan masa mendatang memerlukan analisis perkiraan terhadap suatu rencana investasi. Terdapat dua ukuran/kriteria yang dapat dipergunakan, yaitu: undiscounted criterion dan discounted criterion.

Analisis rasio penerimaan biaya ( $\mathrm{R} / \mathrm{C}$ ratio), analisis rentabilitas dan analisis payback period atau periode pengembalian investasi (PPI). Seperti telah ditulis bahwa analisis keragaan secara undiscounted criterion tidak mempertimbangkan tingkat suku bunga dan nilai investasi. Analisis secara undiscounted criterion dipilih karena sangat sesuai dalam penelitian ini sebab menganalisis skala usaha kecil (artisanal) dan menghitung investasi jangka pendek (kurang dari 1 tahun). 


\section{Analisis $\mathrm{R} / \mathrm{C}$ ratio}

Analisis rasio penerimaan biaya dimaksudkan untuk mengetahui besarnya nilai perbandingan penerimaan dan biaya produksi yang digunakan. Rumus perhitungan analisis ini seperti dikemukakan Sisdjatmiko (1990) dan Hernanto (1998) adalah sebagai berikut :

Kriteria yang digunakan adalah:

$$
R / C \text { ratio }=\frac{\text { Total Penerimaan }}{\text { Total Biaya }}
$$

$\mathrm{R} / \mathrm{C}$ ratio $>1$, berarti usaha menghasilkan keuntungan sehingga layak untuk dijalankan.

$\mathrm{R} / \mathrm{C}$ ratio $=1$, berarti usaha tidak untung dan tidak rugi (impas).

$\mathrm{R} / \mathrm{C}$ ratio $<1$, berarti usaha mengalami kerugian sehingga tidak layak untuk dijalankan.

2. Analisis Rentabilitas

Analisis Rentabilitas adalah suatu analisis yang menunjukkan perbandingan antara laba dengan aktiva atau modal yang menghasilkan laba tersebut. Dengan kata lain rentabilitas adalah kemampuan suatu usaha untuk menghasilkan laba selama periode tertentu. Nilai rentabilitas di atas $25 \%$ menunjukkan bahwa usaha tersebut bekerja pada kondisi efisien dan sebaliknya bila sama atau di bawah 25\% (Riyanto, 2001). Dalam kajian ini pengukuran rentabilitas dilakukan dengan pendekatan "rasio aktiva-laba ekonomi”, dengan rumus sebagai berikut :

$$
\text { Rentabilitas }=\frac{\text { Keuntungan }}{\text { Modal }} \times 100 \%
$$

Laba usaha setelah pajak dalam hal ini adalah jumlah keuntungan bersih yaitu penerimaan total dikurangi dengan biaya total, sedangkan total aktiva adalah total investasi awal.

3. Analisis payback period (PP) atau periode pengembalian investasi (PPI)

Analisis periode pengembalian investasi digunakan untuk mengetahui lamanya perputaran modal/investasi yang digunakan dalam melakukan usaha atau dengan kata lain untuk mengetahui waktu yang dapat digunakan untuk menutup kembali pengeluaran investasi dengan menggunakan keuntungan sebagai perbandingan (Riyanto, 2001). Besarnya nilai periode kembali modal dapat dihitung dengan menggunakan rumus :

$$
\text { Payback Period }(P P)=\frac{\text { Modal }}{\text { Keuntungan }} \times 1 \text { bulan }
$$

Menurut Husnan dan Enny (2004), PP menghitung berapa cepat investasi yang dilakukan bisa kembali. Karena itu hasil perhitungannya dinyatakan dalam satuan waktu (tahun atau bulan).

Konsep yang digunakan adalah Nilai Tukar Nelayan (NTN) yang menurut definisinya, NTN adalah rasio total pendapatan terhadap total pengeluaran rumah tangga nelayan selama periode waktu tertentu (Basuki dkk, 2001). Rumus menghitung NTN seperti berikut ini:

$$
\begin{aligned}
& \operatorname{NTN}_{t}=\frac{Y_{t}}{E_{t}} \\
& \mathrm{Y}_{\mathrm{t}} \quad=\mathrm{Y}_{\mathrm{Ft}}+\mathrm{Y}_{\mathrm{NFt}} \\
& \mathrm{E}_{\mathrm{t}} \quad=\mathrm{E}_{\mathrm{Ft}}+\mathrm{E}_{\mathrm{Kt}} \quad \text { (Basuki dkk, 2001) }
\end{aligned}
$$

Keterangan:

$$
\begin{array}{ll}
\mathrm{Y}_{\mathrm{Ft}} & \text { : total pendapatan nelayan dari usaha perikanan }(\mathrm{Rp}) \\
\mathrm{Y}_{\mathrm{NFt}} & \text { : total pendapatan nelayan dari usaha non perikanan }(\mathrm{Rp}) \\
\mathrm{E}_{\mathrm{Ft}} & \text { : total pengeluaran nelayan untuk usaha perikanan }(\mathrm{Rp}) \\
\mathrm{E}_{\mathrm{Kt}} & \text { : total pengeluaran nelayan untuk konsumsi keluarga nelayan (Rp) } \\
\mathrm{t} & \text { : periode waktu (bulan, tahun, dll) }
\end{array}
$$

Besarnya nilai NTN memberikan gambaran apakah masyarakat nelayan mampu memenuhi kebutuhan subsistensinya. Jika NTN di atas 1 berarti keluarga nelayan memiliki tingkat kesejahteraan cukup baik dalam memenuhi kebutuhan subsistensi (primer) hidupnya dan mempunyai potensi untuk mengkonsumsi kebutuhan non primernya atau menabung (saving). Jika NTN berada di sekitar angka 1 berarti keluarga nelayan hanya mampu mencukupi kebutuhan subsistensinya, sebaliknya jika NTN berada di bawah angka 1 berarti keluarga nelayan memiliki tingkat kesejahteraan rendah dan tidak mampu mencukupi kebutuhan primernya serta mempunyai potensi mengalami defisit anggaran rumah tangganya (dissaving) (Basuki dkk, 2001).

\section{HASIL DAN PEMBAHASAN}

Desa Aromarea adalah salah satu dari 8 (delapan) Desa di Distrik Kosiwo Kabupaten Kepulauan Yapen. Dalam pelaksanaan pembangunan, penduduk menjadi faktor yang sangat dominan. Karena penduduk tidak saja menjadi sasaran tetapi juga menjadi pelaksana dari pembangunan. Oleh karena itu untuk menunjang keberhasilan pembangunan, perkembangan penduduk perlu diarahkan sehingga mempunyai ciri-ciri atau karakteristik yang menguntungkan pembangunan. 
Analisis R/C ratio dalam penelitian ini digunakan untuk mengetahui besarnya nilai perbandingan antara penerimaan/pendapatan dan biaya produksi yang digunakan. Perhitungan R/C ratio usaha penangkapan ikan menggunakan jaring gillnet yang dilakukan nelayan di Desa Aromarea dapat dilihat pada Tabel 1.

Tabel 1. Rata-rata R/C Ratio Usaha Penangkapan Jaring Gillnet

\begin{tabular}{cc}
\hline Uraian & Nilai \\
\hline Pendapatan & Rp. 1.602.273,00 \\
Biaya Total & Rp. 988.636,00 \\
\hline R/C ratio & 1,7 \\
\hline
\end{tabular}

Sumber Data: Hasil Penelitian 2012

Pada Tabel 1 menunjukkan bahwa R/C ratio pada usaha penangkapan ikan dengan alat tangkap jaring gillnet adalah lebih dari $1(>1)$, yang berarti bahwa usaha penangkapan layak dilakukan. Hasil penghitungan $\mathrm{R} / \mathrm{C}$ ratio menunjukkan nilai rata-rata sebesar 1,7 yang menurut Prawiroharjono (2009), menunjukkan bahwa usaha perikanan tangkap jaring gillnet sudah menguntungkan dan artinya bahwa rata-rata setiap nelayan melakukan operasi penangkapan memperoleh penerimaan sebesar 1,7 kali lipat atas biaya-biaya yang dikeluarkan atau dengan kata lain setiap Rp.1,- yang dikeluarkan nelayan untuk melakukan usaha penangkapan maka penerimaan yang dihasilkan sebesar Rp. 1,7 .

Perhitungan rentabilitas merupakan perbandingan antara keuntungan (pendapatan bersih) selama periode tertentu dengan modal yang dipergunakan untuk menghasilkan keuntungan tersebut. Perhitungan rentabilitas penting artinya dalam usaha penangkapan ikan, karena keuntungan yang besar belum merupakan ukuran bahwa usaha penangkapan tersebut telah bekerja dengan efisien. Salah satu ukuran efisiensi adalah melalui perhitungan rentabilitas, yaitu dengan cara membandingkan antara keuntungan yang diperoleh dengan modal investasi yang dikeluarkan. Rentabilitas usaha penangkapan ikan dengan alat tangkap jaring gillnet dapat dilihat pada Tabel 2.

Tabel 2. Rata-rata Rentabilitas Usaha Penangkapan Jaring Gillnet

\begin{tabular}{cc}
\hline Uraian & Nilai \\
\hline Keuntungan & Rp. 613.636,00 \\
Modal & Rp. 988.636,00 \\
\hline Rentabilitas & 62 \\
\hline
\end{tabular}

Sumber Data: Hasil Penelitian 2012

Berdasarkan Tabel 2 dari besarnya nilai rentabilitas usaha penangkapan jaring gillnet dapat ditarik kesimpulan bahwa nilai rentabilitas Desa Aromarea masih rendah. Menurut Riyanto (1998), nilai rentabilitas di atas $25 \%$ menunjukkan bahwa usaha tersebut bekerja pada kondisi efisien dan sebaliknya bila sama atau di bawah $25 \%$. Dari penghitungan rasio rentabilitas usaha penangkapan dengan menggunakan alat tangkap jaring gillnet diperoleh rata-rata rasio rentabilitas sebesar $62 \%$ yang berarti bahwa nilai tersebut $>25 \%$ sehingga usaha tersebut dapat dikatakan sudah menguntungkan, efisien dan layak dalam beroperasi. Riyanto (2001) juga mengatakan, rentabilitas suatu perusahaan/usaha menunjukkan perbandingan antara laba dengan aktiva/modal yang menghasilkan laba. Dengan kata lain rentabilitas adalah kemampuan perusahaan/kegiatan usaha untuk menghasilkan laba. Nilai rentabilitas rata-rata usaha penangkapan ikan dengan alat tangkap jaring gillnet tersebut merupakan nilai laba/keuntungan yang didapatkan dari aktiva/modal investasi awal.

Perhitungan payback period atau periode pengembalian investasi diperlukan untuk mengetahui periode waktu pengembalian investasi sehingga dapat menggambarkan panjangnya waktu yang diperlukan agar dana yang diinvestasikan pada usaha penangkapan ikan dapat diperoleh kembali seluruhnya.

Pada usaha penangkapan ikan dengan alat tangkap jaring gillnet di Desa Aromarea, perhitungan periode kembali investasi merupakan perbandingan antara modal investasi dengan keuntungan (pendapatan bersih) selama 1 bulan. Perhitungan PP usaha penangkapan ikan dengan alat tangkap jaring gillnet dapat dilihat pada Tabel 3.

Tabel 3. Payback Period Usaha Penangkapan Jaring Gillnet

\begin{tabular}{cc}
\hline Uraian & Nilai \\
\hline Modal & Rp. 613.636,00 \\
Keuntungan & Rp. 988.636,00 \\
\hline PP & 1,6 \\
\hline
\end{tabular}

Sumber data: Hasil Penelitian, 2012.

Tingkat pengembalian modal pada usaha dikategorikan cepat jika nilai PP kurang dari 3 tahun $(<3$ tahun). Jika nilai PP lebih dari 3 tahun tetapi kurang dari 5 tahun berarti dikategorikan tingkat pengembalian sedang. Apabila nilai PP lebih dari 5 tahun maka tingkat pengembalian lambat (Riyanto, 2001). Pada usaha perikanan dengan alat tangkap jaring gillnet di Desa Aromarea diperoleh payback period rata-rata 1,6 per bulan. Hal ini berarti nelayan dapat mengembalikan modal usaha dalam waktu kurang dari 2 bulan modal sudah kembali.

Pendapatan nelayan jaring gillnet sangat mempengaruhi tingkat kesejahteraannya karena melalui pendapatan tersebut nelayan harus memenuhi kebutuhan hidup diri dan keluarganya. Besarnya pendapatan nelayan jaring gillnet sangat bervariasi sebab banyak faktor yang mempengaruhinya. Faktor tersebut misalnya faktor alam (musim, cuaca, 
kondisi geografis), faktor teknis (skala usaha dan faktor/sarana produksi) dan faktor non teknis yaitu kondisi sosial budaya masyarakat nelayan.

Basuki, dkk (2001) menyatakan bahwa Nilai Tukar Nelayan (NTN) merupakan salah satu indikator untuk mengukur tingkat kesejahteraan nelayan dalam memenuhi kehidupan subsistensinya pada kurun waktu tertentu (bulan, tahun, dll). Kriteria besaran NTN yang diperoleh dapat lebih rendah, sama atau lebih tinggi dari satu. Jika NTN lebih kecil dari satu (NTN <1) berarti keluarga nelayan mempunyai daya beli lebih rendah untuk dapat memenuhi kebutuhan hidupnya dan berpotensi untuk mengalami defisit anggaran rumah tangganya. Jika NTN berada disekitar angka satu $(\mathrm{NTN}=1)$, berarti keluarga nelayan hanya mampu mencukupi kebutuhan subsistensinya. Sebaliknya jika NTN berada di atas satu (NTN >1), berarti keluarga nelayan mempunyai tingkat kesejahteraan cukup baik untuk memenuhi kebutuhan subsistensinya dan mempunyai potensi untuk mengkonsumsi kebutuhan sekunder atau tersiernya, atau bahkan menabung (saving) dalam bentuk investasi barang. Menurut Satria (2002), pengertian subsistensi diri tidak lagi ditujukan pada pola usaha yang hanya digunakan untuk mencukupi kebutuhan konsumsi sendiri namun kini diartikan sebagai pola usaha yang menjual hasilnya namun hasil penjualan tidak digunakan untuk investasi. Hal ini banyak terjadi pada masyarakat, khususnya yang bergerak di sektor perikanan tangkap dan pertanian.

Berdasarkan hasil penelitian menunjukkan bahwa NTN nelayan jaring gillnet di Desa Aromarea selama bulan Juli sebesar 1,4. Nilai tersebut diperoleh dari perbandingan pendapatan total $\left(\mathrm{Y}_{\mathrm{t}}\right)$ yang terdiri atas pendapatan usaha perikanan $\left(\mathrm{Y}_{\mathrm{Ft}}\right)$ dan pendapatan usaha non perikanan $\left(\mathrm{Y}_{\mathrm{NFt}}\right)$ dengan pengeluaran total $\left(\mathrm{E}_{\mathrm{t}}\right)$ yang terdiri atas pengeluaran usaha perikanan $\left(\mathrm{E}_{\mathrm{Ft}}\right)$ dan pengeluaran konsumsi rumah tangga $\left(\mathrm{E}_{\mathrm{Kt}}\right)$. Perhitungan selengkapnya dapat dilihat pada Lampiran 4.

Menurut data pada Lampiran 4 pendapatan usaha perikanan $\left(\mathrm{Y}_{\mathrm{Ft}}\right)$ diperoleh nilai rata-rata Rp. 1.602.273,- dan pendapatan non usaha perikanan $\left(\mathrm{Y}_{\mathrm{NFt}}\right)$ diperoleh nilai rata-rata Rp. 1.253.409,-. Pendapatan total dari usaha perikanan dan non perikanan $\left(\mathrm{Y}_{\mathrm{t}}\right)$ diperoleh nilai rata-rata $\mathrm{Rp}$. 2.855.682,-. Sedangkan pengeluaran usaha perikanan $\left(\mathrm{E}_{\mathrm{Ft}}\right)$ diperoleh nilai rata-rata Rp. 988.636,-, pengeluaran konsumsi rumah tangga $\left(\mathrm{E}_{\mathrm{Kt}}\right)$ diperoleh nilai rata-rata Rp. 675.000,- dan pengeluaran bercocok tanam serta menokok sagu diperoleh nilai rata-rata sebesar Rp. 362.500,-. Pengeluaran total dari usaha perikanan dan konsumsi rumah tangga diperoleh nilai rata-rata Rp. 1.663.636,-. Sehingga diperoleh pendapatan total Rp. 2.855.682,- dikurangi pengeluaran total Rp. 2.026.136,-- sebesar Rp. 829.546,-. Hal ini menunjukkan bahwa kehidupan nelayan jaring gillnet mempunyai tingkat kesejahteraan cukup baik untuk memenuhi kebutuhan subsistensinya dan mempunyai potensi untuk mengkonsumsi kebutuhan sekunder atau tersiernya, atau bahkan menabung (saving) dengan sisa pendapatan dan pengeluaran per bulan sebesar Rp. 829.546,-

\section{KESIMPULAN}

Kesimpulan yang didapatkan dari hasil penelitian ini adalah sebagai berikut :

1. Aspek sosial ekonomi dan budaya kehidupan nelayan jaring gillnet di Desa Aromarea sangat beragam dengan kondisi yang belum memadai meskipun pada beberapa aspek sudah cukup baik.

2. Analisis keragaan ekonomi secara undiscounted criterion menunjukkan bahwa usaha perikanan jaring gillnet di Desa Aromarea menguntungkan, efisien dan layak beroperasi dengan nilai $\mathrm{R} / \mathrm{C}$ ratio sebesar 1,7 serta rentabilitas sebesar $62 \%$ dan payback period (PP) sebesar 1,6 bulan.

3. Analisis tingkat kesejahteraan nelayan jaring gillnet dengan metode Nilai Tukar Nelayan (NTN) diperoleh hasil NTN pada bulan Juli sebesar 1,4. Yang artinya NTN lebih dari 1, hal ini memberikan informasi bahwa keluarga nelayan mampu memenuhi kebutuhan sekunder atau tersiernya dan mampu menyisihkan uang untuk ditabung sebesar Rp. 829.546,00 per bulan. Jadi, secara umum kehidupan nelayan mempunyai tingkat kesejahteraan cukup baik.

Adapun saran yang dapat diberikan dari hasil penelitian ini adalah bahwa peningkatan pendidikan keluarga, peningkatan mata pencaharian alternatif dan pembinaan nelayan dalam melestarikan lingkungan perlu ditingkatkan melalui sinergisitas yang baik dari pemerinatah dan masyarakat setempat untuk kelestarian ekosistem di Desa Aromarea Kepulauan Yapen Papua.

\section{Ucapan Terimakasih}

Pada kesempatan ini penulis mengucapkan banyak terimakasih kepada Ir. Anhar Solichin,M.Si. dan Ir. Bambang Argo,W. M,Si. yang telah membantu dalam penyusunan penulisan ini, serta keluarga dan teman-teman yang turut berpartisipasi dalam penelitian dan terus memberikan dukungan.

\section{DAFTAR PUSTAKA}

Arikunto, S. 2002. Prosedur Penelitian, Suatu Pendekatan Praktik. PT. Rineka Cipta, Jakarta, 152 hlm. Ayodhyoa, AU. 1981. Metode Penangkapan Ikan. Yayasan Dewi Sri. Bogor.

Basuki, R., PU Hadi, Tri Pranaji, Nyak Ilham, Sugiarto, Hendiarto, B. Winarso, D. Hatnyoto, Iwan Setiawan . 2001. Pedoman Umum Nilai Tukar Nelayan. Dirjen Pesisir dan Pulau-pulau Kecil DKP, Jakarta, 25 hlm.

Husnan, S. dan P. Enny. 2004. Dasar-Dasar Manajemen Keuangan (Edisi Ke IV). UPP (Unit Penerbit dan Percetakan) AMP YKTN, Yogyakarta, $95 \mathrm{hlm}$. 
Kusnadi. 2002. Konflik Sosial Nelayan, Kemiskinan dan Perebutan Sumberdaya Alam. LKiS, Yogyakarta, 266 hlm. Riduwan. 2006. Skala Pengukuran Variabel-Variabel Penelitian. CV. Alfabeta, Bandung, 111 hlm.

Riyanto, 2001. Dasar-dasar Pembelanjaan Perusahaan. Yayasan Penerbit Universitas Gajah Mada, Yogyakarta, 145 hlm.

Riyanto, B. 1998. Metode Riset dan Aplikasinya dalam Riset Pemasaran. Biro Statistika, Jakarta, 125 hlm.

Satria, A. 2002. Pengantar Sosiologi Masyarakat Pesisir. PT Pustaka Cidecindo, Jakarta, 130 hlm.

Sisdjatmiko. 1990. Kajian Dasar Pengantar Teori Ekonomi Mikro. Rineka Cipta, Jakarta, 86 hlm. 